\title{
Tiroit cerrahisi sonrasında görülen komplikasyonlar
}

\section{Complications of thyroid surgery}

\author{
Kağan Karabulut*, Cafer Polat*
}

Ondokuz Mayıs Üniversitesi, Tıp Fakültesi, Genel Cerrahi Anabilim Dalı, Samsun, Türkiye

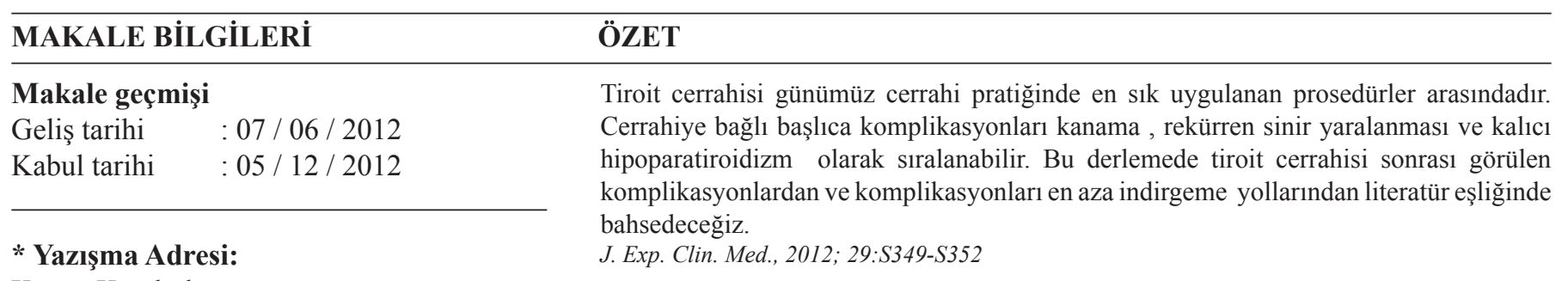

Kağan Karabulut

Ondokuz Mayıs Üniversitesi,

Tıp Fakültesi,

Genel Cerrahi Anabilim Dall,

Kurupelit/Samsun

\begin{abstract}
Thyroid surgery is among the most frequent procedure which is applied in today's surgery practice. The main complications related with surgery are hemorrhage, recurrent nerve injury and permanent hypoparathyroidism. In this review we discussed about complications seen after thyroid surgery and the ways of minimising complications accompanied by literature.

J. Exp. Clin. Med., 2012; 29:S349-S352
\end{abstract}

Anahtar Kelimeler:

Tiroit cerrahisi

Komplikasyonlar

Reküren sinir yaralanması

Kanama

Hipoparatiroidizm

Keywords:

Thyroid surgery

Complications

Recurrent nerve injury

Hemorrhage

Hypoparathyroidism

\section{Giriş}

Tiroit cerrahisinin temelleri Tehodor Kocher tarafindan atılmış ve günümüz cerrahi pratiğinde yaygın uygulanan prosedürler arasında yerini almıştır (Kievit ve ark., 2005) . Tiroit cerrahisinin tarihçesi nodül eksizyonundan total tiroidektomiye kadar geniş bir yelpazede seyreder. Bu derlemede tiroit cerrahisi sonrası görülen komplikasyonlardan ve komplikasyonları en aza indirgeme yollarından literatür eşliğinde bahsedeceğiz. Tiroit cerrahisi sonrası gelişen komplikasyonları genel ve özel (cerrahiye bağlı) komplikasyonlar olarak ikiye ayrilir:

Genel komplikasyonlar

Bu komplikasyonlar yapılan cerrahi işlemle ilgisi olma- yan ve hastanın yandaş hastalıklarına bağlı gelişen kardiak ve pulmoner komplikasyonlardır. Genellikle düşük oranda mortalite ve morbiditeye neden olur (Kievit ve ark., 2005).

\section{Cerrahiye bağlı komplikasyonlar \\ Ödem}

Tiroit cerrahisi sonrasında ödem sık görülmez. Fakat ödem riski tiroit cerrahisi ile beraber yapılan boyun disseksiyonlarında artmaktadır (Machens ve ark., 2002; Scollo ve ark., 2003). Ödemin oluşumuna neden olan etkenler ameliyat alanında azalmış lenfatik ve venöz drenajdır. Ödem gelişmesi durumlarda ödemi engellemek için baş yükseltilir ve gerekli durumlarda kortikosteroid verilmesi ile tedavi edilebilir. 


\section{Kanama}

Postoperatif kanama, cilt altında ekimoz gibi sadece gözlemle tedavi edilebileceği gibi reeksplorasyonu gerektirebilecek hayatı tehdit edici solunum yolunun tıkanıklığında neden olabilen ciddi bir komplikasyondur. Postoperatif kanama \% 0,36 ile \% 4,3 oranında görülür (Frick ve Largiadèr, 1991; Lacoste ve ark., 1993). Ameliyat sonrası kanama genellikle ilk 24 saat içinde gelişir (Shaha ve Jaffe, 1994; Abbas ve ark., 2001). Ciddi bir komplikasyon olmasına rağmen vokal kord paralizisi yada hipokalsemiye göre daha az gelişen bir komplikasyondur. Kanama nedenleri ameliyat sirasinda yeterli kanama kontrolünün yapılmaması, hastanın uyanma esnasında ya da derlenme esnasında öğürme, öksürme, valsalva manevrası ile kan basıncının artmasına bağlı koterize edilen venlerin tekrar açılması, yetersiz damar ligasyonu ya da kesilen tiroit bezinden sızma sonucunda oluşur (Shaha ve Jaffe, 1994).

\section{Ameliyat sonrası kanama semptomları}

Solunum sıkıntısı, boyunda ağrı, basınç hissi, boyunda ilerleyici şişme, dikiş hattında kanama, stridor, ameliyat sahasına konan drenden gelen miktarın artması ve ciltte ekimozdur (Harding ve ark., 2006). Kanama strep kasların üstünden ve derininden olabilir. Özellikle strep kasların derininden olan kanamalarda solunum yolu tıkanıklığı açısından dikkatli olunmalıdır. Hematoma bağlı stridor ve hipoksi gelişmesi durumunda acil eksplorasyon gereklidir (Sanabria ve ark., 2007; Rosenbaum ve ark., 2008).

Eksplorasyon genel anestesi altında ameliyathane koşullarında yapılmalıdır. Solunum sıkıntısı gelişen bazı hastalarda yatak başında acil olarak dikişlerin açılarak hematomun drenajının sağlanması, hastanın solunum yollarındaki baskının azaltılarak ameliyata alınması gerekebilir. Böylece hastanın solunumu rahatlatılmış olup endotrakeal entubasyonu da kolaylaştırılmış olur. Eksplorasyonda tüm katlar ayrı ayrı dikkatlice araştırılmalıdır. Hematom boşaltılmalı, kanama alanı yıkanmalı ve kanama odağı tespit edilmeye çalışılmalıdır. Kanama odağının damarsal kaynaklı olduğu düşünülüyorsa kanayan damar dikkatlice bulunmalı ve kanama kontrol altına alınmalıdır. Vasküler kanama odağını ararken kontrolsüz ve görmeden yapılacak hareketlerden sakınılmalıdır. Bu hareketler kanamayı arttırabilir ya da kanama kontrol altına alınmaya çalışılırken sinir yaralanmasına neden olabilir. Cerrahlar ameliyat sonrası kanamayı engellemek ve ameliyat alanında sıvı birikimini azaltmak için ameliyat alanına genellikle baskılı pansuman uygularlar. Piromchai ve ark. (2008) yaptığı prospektif randomize çalışmada baskılı pansuman ve baskılı yapılmayan pansuman karşılaştırılmış her iki grupta da ameliyat alanında sıvı birikimi açısından fark bulunamamıştır. Yine de ameliyat sonrası hematomu engellemekte baskılı pansuman faydalı olabilir. Ameliyat sonrası yapılan pansumanın tüm boyunu sarması durumunda hematomun erken saptanmasına engel olabilir. Ameliyat sonrası kanama genellikle ilk 24 saatte görülür. Bu nedenle ilk 24 saate kanama semptomlarına dikkat edilmeli ve bunlara karşı uyanık olmak gerekir.

\section{Kalıcı/geçici rekürren larengial sinir hasarı}

Tiroit cerrahisi sonrası gelişen rekürren sinir hasarı cerrahların en çekindikleri ve korktukları komplikasyondur. Sinir hasarı ses kalitesinin değişimine neden olabileceği gibi solunum yetmezliğine bağlı trakeostomi açılması ile sonuçla- nabilecek ciddi bir morbiditeye neden olabilir. Tiroidektomi sırasında sinirlerin ortaya konulmaması sinir hasarının oluşmasının en önemli nedenidir. Bu nedenle total/totale yakın tiroidektomi yapılması planlanan hastalarda ve reoperasyon yapılacak hastalarda ameliyat sırasında mutlaka rekürren sinirlerin görülmesi gerekmektedir. Rekürren sinir hasarını önlemek için sağ ve sol rekürren sinirlerin trasesi ve anatomik varyasyonlarının bilinmesi gereklidir. Literatürde rekürren larengial sinir (RNL) bağlı kompikasyonlar \% 0-5 arasında bildirilmektedir (Martensson ve ark., 1985; Shindo ve ark., 1995; Hermann ve ark., 2002). RLN hasarından kaçınmak ya da en aza indirgemek için ameliyat sırasında RLN sinirin ortaya konulması amacıyla stratejiler geliştirilmiştir. En sık kullanılan yol ise sinirin extralarengial trasesinin disseksiyonu ve görsel olarak sinirin ortaya konulmasıdır. Bunun dışında sinirin ameliyat sırasında elektriksel olarak uyarılarak krikofarengial kasın kasılmaların gözlenip sinirin ortaya konulması ve sinir devamlılığı hakkında bilgi edinilmesidir. Üçüncü yol ise intraoperatif sinir monitorizasyonu ile RLN sinirinin disseksiyonudur. RLN ameliyat sırasında görsel olarak tanımlamak için dört farklı yol vardır:

1-RLN arteria karotis communisin arkasından arteri çaprazladığı yerde bulunabilir. Bu seviyede sinir dorsal olarak uzanır. Arterin mediokranial yüzeyi boyunca lateralden medial ve dorsal yöne özafagus ve trakea ya doğru disseksiyon yapılarak her zaman bulunabilir. Bu yöntemin avantajı bu seviyede sinir dallara ayrılmadığı için daha iyi görülebilir. Ayrıca reoperasyonlar da boyun bu seviyede bozulmamış olabilir bu da sinirin kolayca tanımlanmasını sağlar. Bu yöntemin dezavantajı ise boyunun kaudalinde yağl1, lenfoid ve gevşek dokuların disseksiyonunu gerektirilir.

2-RLN Berry ligamanı seviyesinde kirikotrioid kasa girdiği yerde tanımlanabilir. Bu seviyede sinir daha sabit durumdadır. Dezavantajı ise kasa girdiği yerin tiroidin arkasında olmasıdır. Bu bölgede yapılan disseksiyon sınrasında bölgenin hipervasküler olması nedeniyle kanama olabilir. Kanama sinire zarar vermeden konrol altına alınması gereklidir. $\mathrm{Bu}$ alanda kanama kontrol altına alınırken koter kullanılmamalı, kullanılması gerekiyorsa da sinire beş mm uzaktaki kanamalarda bipolar koter kullanılmalıdır.

3-Trakea karşı alt kutbun altındaki yağlı gözeli ve lenfoid dokulara nazikçe palpe edilip parmak yavaşca ventral ve dorsal olarak öne ve arkaya yavaşca hareket ettirilerek trakea üzerinde sinir hissedilebilir. Sinir palpe edildikten sonra konnektif doku sinir doğrultusunda dikkatlice ayrılarak sinir ortaya konulabilir. Sinir hasarından korunmak için palpasyon ve disseksiyonun birbiri ardına yapılması gerekmektedir.

4-RLN monitorizasyonu sinirin tanımlanmasında kullanılabilir (Kievit ve ark., 2005). Özellikle reoperasyonda sinirin ortaya konulmasında daha önceden kullanılmayan planların kullanılması sinir hasarını engelleyebilir.

Postoperatif ses kısıklığının gelişmesinde rol oynayan birçok faktör vardır. Ameliyat sonrası ilk 2-5 gün içinde oluşan ses kısıklığının nedeni ameliyat sahasındaki ödeme bağlı gelişir (Altı aydan kısa süren ses kısıklığının nedeni ameliyat sırasındaki traksiyona bağlı akson hasarıdır). Sinir hasarına bağlı vokal kord disfonkisyonu bir yıldan fazla devam ederse sinir hasarı kalıcıdır (Kievit ve ark., 2005).

Süperior larengial sinir hasarı

Süperior larengial sinir reküren larengial sinir gibi vagal 
sinirden çıkar. Süperior larengial sinir ve bu sinirin internal dalı standart tiroidektomi alanının üstünde kalmaktadır. Bu nedenle tiroidektomi sırasında bu sinirle karşılaşılmaz. Süperior larengial sinirin internal dalı süperior larengial arterin üstünde tirohyoid membrana girer. Süperior larengial sinirin eksternal dalı superior medial arterin medialine yakın seyreder ve krikotiroid kası inerve eder. Tiroit üst polü besleyen damarları çaprazladığı yer ve krikotiroid kası innerve etmesi tiroit üst polün serbestlenmesi sırasında sinirin yaralanma riski olabilir.

Süperior larengial sinirin eksternal dalının yaralanmasını engellemek için tiroit üst polünün vasküler pedikül disseksiyonunun dikkatli yapılması gerekmektedir. Vasküler pedikül üst polün üzerinde disseke edilecekse sinir ve dalları bulunup korunmalıdır. Eğer vasküler yapıların terminal dalları ayrı ayrı bağlanacaksa sinirin görülmesine gerek yoktur. Cerrahi sırasında sinirin zarar görmesine bağlı ses kısıklığı, ses zayıflı̆̆ı/yorgunluğu, düşük ses volümüne neden olabilir. Sinir zararı iki taraflı olursa yutkunma zorluğuna neden olur (Kievit ve ark., 2005).

\section{Hipoparatiroidizm}

Tiroidektomi sonrası kalıcı yada geçiçi hipoparatiroidizm gelişebilir. Kalıcı hipoparatirodizm \% 0,8 ile 3 oranında görülse de geçici hipoparatiroidizm \% 20 oranında daha sık görülür (Hundahl ve ark., 2000; Richmond ve ark., 2007; Serpell ve ark., 2007). Hipoparatiroidizm oluşma nedenleri paratiroit bezinin vaskülarizasyonun bozulması sonrası gelişen iskemi ya da paratiroit bezinin tiroidektomi sırasında alınmasıdır.

Paratiroit bezleri tiroit posterolateral bezinin önünde bulunurlar ve arterleri inferior tiroit arterden kaynaklanır. Yine de bu arterin bağlanması sonrasında hipoparatiroidizm gelişmez çünkü paratiroit bezleri ayrıca süperior tiroit arter, özafajiyal ya da trakeal arterlerden kollateral ile beslenirler (Burke ve ark., 1998). Paratiroit bezlerin cerrahi ekplorasyonu sırasında ortaya konulması için pozisyonu, tiroit bezinden bağımsız mobilizasyon, kahverengiye benzer renkte, düzgün sınırlı yüzeyinin olması, vasküler pediküle sahip olması, manuplasyon sonrası kolay kanama olması, küçük yağlı doku görüntüsü gibi özellikleri kullanılabilir (Kievit ve ark., 2005). Hipoparatiroidizmden korunmak için tüm paratiroit bezleri ortaya konulmalı, bezler gereksiz yere mobilize edilmeme- li yada disseksiyon sırasında devaskülarize edilmemelidir. Eğer bezler iskemik görüldüyse ya da kaza ile çıkarılmışsa sternokleoid kasa yada dominant olmayan kolun brakioradial kasına ototransplantasyon yapılmalıdır. Hiçbir paratiroit bezi iskemik şekilde bırakılmamalı ototransplantasyon mutlaka yapılmalıdır. Hipoparatiroidizme bağlı gelişen hipokalsemi derinliğine bağlı olarak perioral/distal ekstremitede palestesi, muskuler kramplar, Trousseau ve Chvostek işareti, Larengial stridor ve konvulsiyon gelişebilir. Özellikle stridor yada konvulsiyon fatal seyreden durumlardır (Richmond ve ark., 1998). Tedavi edilmemiş hipoparatirodizme bağlı olarak katarakt gelişimine, bazal ganglionlarda kalsifikasyonlara, tekrarlayıcı felç, osteomalazi ve psikiyatrik semptomlara neden olabilir (Richmond ve ark., 1998).

Tiroit cerrahisinde kullanılan yeni teknolojiler ve bu teknolojilerin komplikasyonlar üzerine etkisi

Tiroidektomi için tiroide ait vasküler yapıları, etraf doku ve organlar ile arasındaki bağ dokunun ortaya konulması, ve kesilmesi gerekmektedir. Konvansiyonel tiroit cerrahisinde yapılar ortaya konulur, bağlanır ve kesilir. Teknolojinin ilerlemesi ile tiroidektomi için birçok yeni teknoloji kullanılmaya başlanılmıştır. Bu teknolojiler içinde ultrasonik dissektör (Harmonic Scalpel, Johnson\&Johnson) ve bipolar vessel sealing system, (LİgaSure, Coviden) en çok kullanılan teknolojilerdir.

Cirocchi ve ark. (2010) yaptığı ultrasonik dissektör ile konvansiyel sistemin karşılaştırılmasını amaçlayan meta analizde ultrasonik dissektörün ameliyat süresini, ameliyat esnasındaki kanama ve ameliyat sonrası ilk 24 saatteki drenaj miktarını azalttığını gösterilmiştir. Fakat ameliyat sonrası komplikasyonlar (kalıc1/ geçici larengial sinir hasarı, kalıcı/ geçici hipokalsemi) karşılaştırıldığında istatiksel olarak anlamlı bir fark bulunamamıştır.

Yao ve ark. (2009) yaptığ ligasure ile konvansiyonel tiroidektominin karşılaştırılmasını amaçlayan meta analizde Cirocchi ve ark. (2010) yaptığı çalışmaya benzer sonuçlar bulunmuş ve ameliyat sonrası komplikasyonları karşılaştırılmasında istatiksel olarak anlamlı bir fark bulunamamıştır. Her iki çalışmanın ortak kanısı kullanılan iki yeni teknolojinin ameliyat süresini kısalttığıdır.

\section{KAYNAKLAR}

Abbas, G., Dubner, S., Heller, K.S., 2001. Re-operation for bleeding after thyroidectomy and parathyroidectomy. Head Neck. 23, 544-546.

Burge, M.R., Zeise, T.M., Johnsen, M.W., Conway, M.J., Qualls, C.R., 1998. Risks of complication following thyroidectomy. J. Gen. Intern. Med. 13, 24-31.

Cirocchi, R., D'Ajello, F., Trastulli, S., Santoro, A., Di Rocco, G., Vendettuoli, D., Rondelli, F., Giannotti, D., Sanguinetti, A., Minelli, L., Redler, A., Basoli, A., Avenia, N., 2010. Meta-analysis of thyroidectomy with ultrasonic dissector versus conventional clamp and tie. World J. Surg. Oncol. 8, 112 .

Frick, T., Largiadèr, F., 1991. Perioperative complications in thyroid gland surgery. Langenbecks Arch. Chir. 376, 291-294.

Harding, J., Sebag, F., Sierra, M., Palazzo, F.F., Henry, J.F., 2006. Thyroid surgery: Postoperative hematoma--prevention and treatment. Langenbecks Arch. Surg. 391, 169-173.

Hermann, M., Alk, G., Roka, R., Glaser, K., Freissmuth, M., 2002. Laryngeal recurrent nerve injury in surgery for benign thyroid diseases: Effect of nerve dissection and impact of individual surgeon in more than 27,000 nerves at risk. Ann. Surg. 235, 261-268.

Hundahl, S.A., Cady, B., Cunningham, M.P., Mazzaferri, E., McKee, R.F., Rosai, J., Shah, J.P., Fremgen, A.M., Stewart, A.K., Hölzer, S., 2000. Initial results from a prospective cohort study of 5583 cases of thyroid carcinoma treated in the united states during 1996. U.S. and German Thyroid Cancer Study Group. An American College of Surgeons Commission on Cancer Patient Care Evaluation study. Cancer. 89, 202.

Kievit, J., Bonsing, B.A., Songun, I., Van de Velde, C.J.H., 2005. Occurrence and prevention of complications in thyroid surgery: Textbook of endocrine surgery, pp. 207-214 Editors: Orlo H. Clark, Quan-Yang Duh, Electron Kebebew.

Lacoste, L., Gineste, D., Karayan, J., Montaz, N., Lehuede, M.S., Girault, M., Bernit, A.F., Barbier, J., Fusciardi, J., 1993. Airway complications in thyroid surgery. Ann. Oto. Rhinol. Laryn. 102, 441-446. 
Mårtensson, H., Terins, J., 1985. Recurrent laryngeal nerve palsy in thyroid gland surgery related to operations and nerves at risk. Arch. Surg. $120,475-477$.

Machens, A., Hinze, R., Thomusch, O., Dralle, H., 2002. Pattern of nodal metastasis for primary and reoperative thyroid cancer. World J. Surg. 26, 22-28.

Piromchai, P., Vatanasapt, P., Reechaipichitkul, W., Phuttharak, W., Thanaviratananich, S., 2008. Is the routine pressure dressing after thyroidectomy necessary? A prospective randomized controlled study. BMC Ear Nose Throat Disord. 20, 1

Richmond, B.K., Eads, K., Flaherty, S., Belcher, M., Runyon, D., 2007. Complications of thyroidectomy and parathyroidectomy in the rural community hospital setting. Am. Surgeon. 73, 332.

Rosenbaum, M.A., Haridas, M., McHenry, C.R., 2008. Life-threatening neck hematoma complicating thyroid and parathyroid surgery. Am. J. Surg. 195, 339-343.

Sanabria, A., Carvalho, A.L., Silver, C.E., Rinaldo, A., Shaha, A.R., Kowalski, L.P., Ferlito, A., 2007. Routine drainage after thyroid surgery-a meta-analysis. J. Surg. Oncol. 96, 273-280.

Scollo, C., Baudin, E., Travagli, J.P., Caillou, B., Bellon, N., Leboulleux, S., Schlumberger, M., 2003. Rationale for central and bilateral lymph node dissection in sporadic and hereditary medullary thyroid cancer. J. Clin. Endocr. Metab. 88, 2070-2075.

Serpell, J.W., Phan, D., 2007. Safety of total thyroidectomy. A.N.Z. J. Surg. 77, 15.

Shaha, A.R., Jaffe, B.M., 1994. Practical management of post-thyroidectomy hematoma. J. Surg. Oncol. 57, 235-238.

Shindo, M.L., Sinha, U.K., Rice, D.H., 1995. Safety of thyroidectomy in residency: A review of 186 consecutive cases. Laryngoscope. 105, 1173-1175.

Yao, H.S., Wang, Q., Wang, W.J., Ruan, C.P., 2009. Prospective clinical trials of thyroidectomy with LigaSure vs conventional vessel ligation: A systematic review and meta-analysis. Arch. Surg. 144, 1167-1174. 